\title{
UTILIZAÇÃO DE MAPAS CONCEITUAIS COMO ESTRATÉGIA DE INOVAÇÃO METODOLÓGICA: RELATO DE EXPERIÊNCIA
}

\author{
Karla Rona da Silva ${ }^{1}$ \\ Marina Dayrell de Oliveira Lima ${ }^{2}$ \\ Leila de Fátima Santos ${ }^{3}$
}

\section{RESUMO}

As constantes mudanças do mundo moderno e o avanço tecnológico têm impulsionado a educação a encontrar formas inovadoras para a promoção do saber. A construção dos mapas conceituais pode ser inovadora, auxiliando no processo ensino-aprendizagem baseado na ação ativa dos envolvidos. Assim, objetivamos relatar a utilização da metodologia de elaboração de mapas conceituais como ferramenta de ensino-aprendizagem na área da saúde, utilizando um relato de experiência docente. Participaram da experiência trinta alunos do 8 o período de um curso noturno de graduação e uma monitora. Nossos resultados demonstraram que a utilização de mapas conceituais para sistematização de conceitos foi bem aceita pelos educandos e que essa estratégia é entendida como uma prática inovadora diferencial para a aprendizagem significativa sob o ponto de vista do educador. Concluímos que práticas metodológicas inovadoras, que permitem ao educando participar ativamente do processo de ensino-aprendizagem, podem se refletir na construção da carreira acadêmica e gerar impactos positivos à dinâmica profissional desse sujeito.

Palavras-chave: Mapas conceituais. Aprendizagem significativa. Difusão de inovações. Docência.

\footnotetext{
${ }^{1}$ Escola de Enfermagem, Universidade Federal de Minas Gerais, Belo Horizonte, MG, Brasil.

${ }^{2}$ Centro Universitário UNA, Belo Horizonte, MG, Brasil.

${ }^{3}$ Faculdade Ciências Médicas de Minas Gerais, Belo Horizonte, MG, Brasil.
} 


\title{
USE OF CONCEPTUAL MAPS AS STRATEGY OF METHODOLOGICAL INNOVATION: AN EXPERIENCE REPORT
}

Karla Rona da Silva

Marina Dayrell de Oliveira Lima

Leila de Fátima Santos

\begin{abstract}
The constant changes of the modern world and the technological advances have driven Education to find innovative ways to promote knowledge. The construction of concept maps can be innovative, assisting in the teaching-learning process based on the active action of the ones involved. Thus, we aimed to report the use of the methodology of concept maps building as a teaching-learning tool in health area, using a teaching experience report. Thirty students from the 8th period of an evening undergraduate course and a monitor took part in the experience. Our results demonstrated that the use of concept maps for the systematization of concepts was well accepted by the students and that this strategy is understood as an innovative differential practice for meaningful learning under the educator's point of view. We conclude that innovative methodological practices, which allow the student to actively participate in the teaching-learning process, can be reflected in the construction of his academic career and generate positive impacts on his professional dynamics.
\end{abstract}

Keywords: Conceptual maps. Meaningful learning. Diffusion of innovations. Teaching. 


\section{INTRODUÇÃO}

Utilizar-se de estratégias de inovação em sala de aula, atualmente, é algo desafiador e necessário à prática docente. As constantes mudanças do mundo moderno e o avanço tecnológico têm impulsionado a educação a encontrar formas diferenciadas para a promoção do saber (MANTOVANI, 2008). Entretanto, essa nova concepção parece ainda muito tímida em nosso meio.

Para que ocorra a mudança significativa no processo de ensino-aprendizagem, as metodologias de inovação devem ser utilizadas como ferramentas pedagógicas, levando o aluno à investigação, ao levantamento de hipóteses, possibilitando revisões nas ideias iniciais que ele apresenta, de forma a favorecer a construção do conhecimento (VIEIRA, 2005).

O desenvolvimento de diferentes competências para ensinar e aprender converge para uma ação pedagógica crítica e transformadora, e a utilização de ferramentas e recursos das tecnologias educacionais pode significar aprender a aprender, o que modifica os paradigmas educacionais vigentes até então e aponta para a necessidade de modificações nos papéis dos sujeitos envolvidos nesse processo (PRADO; VAZ; ALMEIDA, 2011).

A construção de mapas conceituais, tema alvo deste estudo, refere-se a uma estratégia metodológica inovadora, que pode auxiliar no alcance de diferentes competências.

O mapa conceitual pode ser definido como uma ferramenta para organizar e representar conhecimento. Com base na teoria da aprendizagem significativa de Ausubel (2000), ele é determinado por uma representação gráfica, em duas dimensões, de um conjunto de conceitos, construído de tal forma que as relações entre eles sejam evidentes (DUTRA; FAGUNDES; CANAS, 2004).

A teoria de aprendizagem significativa de Ausubel propõe que os conhecimentos prévios dos alunos sejam valorizados, para que se possam construir estruturas mentais utilizando, como meio, mapas conceituais que permitem descobrir e redescobrir outros conhecimentos, caracterizando, assim, uma aprendizagem prazerosa e eficaz (PELIZZARI et al., 2002).

No Brasil, os mapas conceituais são utilizados de forma muito flexível, para ensinar a organizar conteúdos, sistematizar temas densos, estabelecer relações explícitas entre o novo conhecimento e o já existente e dar significado aos novos conhecimentos. Assim, permite ao 
discente estruturar o pensamento, por comparações com modelos ou mesmo por organizações de estratégias que facilitem a aprendizagem significativa (MOREIRA, 2010).

"A aprendizagem significativa envolve a assimilação de novos conceitos e proposições em estruturas cognitivas existentes" (NOVAK, 1993, p. 52). Um mapa conceitual é uma representação gráfica em que os nós, pontos ou vértices representam conceitos, e as ligações (arcos ou linhas) retratam as relações entre os conceitos (NOVAK, 2003).

Assim, entende-se que os mapas conceituais podem auxiliar os discentes e docentes na construção de um processo de ensino-aprendizagem baseado na ação ativa de todos os envolvidos, podendo proporcionar relações significativas entre conceitos ensinados em uma única aula, em uma unidade de estudo ou em um curso inteiro (MOREIRA, 2010).

A partir de tais reflexões, entendemos ser relevante compartilhar a experiência acadêmica com a utilização de mapas conceituais em uma disciplina da graduação na área da saúde.

O objetivo do artigo é relatar a aplicação da metodologia de elaboração de mapas conceituais como ferramenta de ensino-aprendizagem na área da saúde, utilizando dados da vivência docente e discente em sala de aula, ocorrida no primeiro semestre de 2015.

\section{BUSCA POR ESTRATÉGIAS DE INOVAÇÃO METODOLÓGICA E ELEIÇÃO DO MAPA CONCEITUAL}

A busca por estratégias de inovação metodológica sempre fez parte da rotina de trabalho da docente relatora do estudo e se revelou ainda mais forte quando ela assumiu uma disciplina obrigatória, teórica, extremamente densa e crucial à formação discente, ofertada para alunos de um curso de graduação noturno, às sextas-feiras, com quatro horários geminados.

Para efetivação das práticas de inovação, fazem-se necessárias a adesão tanto do corpo docente como dos discentes à proposta e, da mesma forma, a conscientização deles a respeito do trabalho a ser desenvolvido. É preciso que todos se envolvam e compreendam a essência de participarem como seres ativos no processo de construção da própria formação. No entanto, compete ao docente refletir criticamente sobre as práticas que adota e buscar estratégias para melhorar as práticas futuras (FREIRE, 1996). 
Assim, foi identificada a necessidade de se buscarem estratégias para melhor capacitação e inovação em sala de aula, estimulando a efetiva participação dos educandos. Nessa busca, foram encontrados os Percursos Formativos em Docência do Ensino Superior, que são ofertados pela Diretoria de Inovação e Metodologias de Ensino - GIZ, vinculada à Pró-Reitoria de Graduação da Universidade Federal de Minas Gerais (PROGRAD/UFMG), que tem como foco a inovação e as metodologias de ensino.

Os cursos, ou percursos, são disponibilizados para os professores da UFMG e para os alunos da pós-graduação (mestrado e doutorado), com atividades presenciais e online, o que favorece o desenvolvimento e a adesão às práticas propostas, com carga horária total de 60 horas.

Como mencionado, a formação oferece várias possibilidades de inovação metodológica em sala de aula, dentre elas, a utilização dos mapas conceituais. O curso foi realizado no primeiro semestre de 2015, tendo a docente concluído todas as etapas com afinco, de forma a assegurar a confiabilidade e o domínio frente à metodologia descrita. Assim, a descoberta dos mapas conceituais foi um grande avanço para a prática da docente que vem utilizando-a de forma sistemática na disciplina em questão.

É notória a importância da capacitação permanente do educador, por meio de cursos, seminários, palestras, dentre outros, para tentar atender as necessidades educacionais atuais, refletindo-se na educação de qualidade, principalmente para lidar com um alunado que tem perfil diferenciado a cada ano (MELCHIOR, 2001).

A capacitação permanente do docente é algo fundamental, sendo preciso considerar o desenvolvimento profissional como um processo constante e que acontece ao longo de toda a carreira, abrangendo os sujeitos envolvidos nas políticas existentes e em construção, melhorando a base do conhecimento dele e criando comunidades de aprendizagem (LEITE, 2013).

\section{PREPARO DOS EDUCANDOS PARA UTILIZAÇÃO DOS MAPAS CONCEITUAIS}

As estratégias diferenciadas utilizadas em sala de aula dão uma motivação maior ao aluno, que tende a se mostrar mais interessado. O aluno passa a buscar informações para além das solicitadas pelo educador. Ele pesquisa, questiona e tem prazer pelo saber (MOREIRA, 2010). 
Ponderando que o discente é o sujeito ativo no processo de ensino-aprendizagem, o educador deve levar em conta os interesses desse agente, partindo das vivências, experiências e da realidade que ele possui. Deve propor atividades que permitam ao discente se expressar, trocar opiniões, questionar, pesquisar, descobrir e colaborar com a busca de soluções para resolução de problemas. Ademais, cabe mencionar que as práticas diferenciadas proporcionam ao aluno uma aprendizagem através de trocas, respeito mútuo e colaboração, de maneira que o conteúdo seja compartilhado de forma unificada, e não fragmentada (FAGUNDES; MAÇADA; SATO, 2000).

Participaram da construção dos mapas conceituais uma monitora e trinta alunos do 8 o período de um curso de graduação com o total de nove períodos. Todos os participantes estavam regularmente matriculados na disciplina, que é obrigatória; a monitora era aluna da pósgraduação da UFMG (mestrado/bolsista).

Ao serem interpelados sobre o conhecimento prévio referente à elaboração de mapas conceituais, três alunos mencionaram já terem ouvido falar algo sobre essa ferramenta, porém nunca a haviam utilizado na prática. A monitora afirmou já ter lido alguns textos sobre o uso de mapas conceituais, mas também nunca os havia utilizado. Os demais afirmaram nunca terem ouvido falar dessa metodologia e se mostraram bem receptivos à nova proposta.

Essa reação dos discentes, de pronto aceite à nova metodologia, contraria a afirmativa de que, perante uma situação de aprendizagem nova, para a qual são necessárias competências que ainda não estão desenvolvidas, em que thes são pedidos envolvimento e responsabilização, os alunos vivem sentimentos de estarem perdidos, de incompetência, de não serem capazes (BAPTISTA; FREIRE; FREIRE, 2013).

O preparo dos educandos e da monitora se deu em quatro etapas. A 1a etapa foi uma contextualização teórica, em que se realizou uma breve explicação para a turma sobre os âmbitos histórico, teórico e operacional dos mapas conceituais. Foram ressaltadas a aplicabilidade, as possibilidades de apoio ao desenvolvimento de habilidades e competências, a relevância para a aprendizagem significativa, a capacidade de desenvolvimento de atividades grupais, a aplicabilidade na sistematização e a revisão dos conteúdos, assim como a importância dessa ferramenta na inovação metodológica. 
$\mathrm{Na} 2$ a etapa foram apresentados exemplos de mapas conceituais (disponíveis em meio eletrônico) desenvolvidos por outros grupos discentes, de forma a ilustrar a prática para melhor visualização e entendimento da ferramenta.

A 3a etapa foi caracterizada por oportunizar aos discentes a possibilidade de confeccionar um mapa conceitual manual. Nessa etapa, após breve discussão sobre a metodologia, como forma de avaliar o entendimento da turma, foi proposta a construção coletiva de um mapa conceitual. Foi elencado um tema hipotético e, assim, foram elaborados, de forma conjunta, os mapas conceituais referentes a esse conceito. A partir daí, concluiu-se que os educandos compreenderam a metodologia, mesmo que de forma bem incipiente.

E, por fim, na 4ạ etapa, fomentou-se a ampliação da concepção teórica. Nessa etapa, foram disponibilizados alguns artigos para análise em ambiente externo, objetivando ampliar os conceitos e diretrizes da metodologia. Também foram explicitados os softwares disponíveis gratuitamente para a confecção de mapas conceituais, estimulando os educandos à navegação investigativa, como forma de conhecimento.

Além dos artigos específicos sobre mapas conceituais, os discentes foram orientados a ler um artigo sobre revisão histórica das políticas públicas de saúde no Brasil (um dos temas da disciplina), para posterior discussão e apresentação em sala de aula.

\section{ATIVIDADES UTILIZANDO MAPAS CONCEITUAIS: MAPAS MANUAIS E USO DOS SOFTWARES}

Em um segundo momento (aula posterior), os alunos foram estimulados a falar sobre o conhecimento adquirido com as leituras dos artigos sobre os mapas conceituais e foram unânimes em afirmar que a metodologia parecia muito interessante, mas sentiam a necessidade de operacionalizá-la.

Com isso, a turma foi dividida em cinco grupos, e, com o apoio da monitora, iniciou-se uma prática com o artigo (tema da disciplina) lido. O texto sobre revisão histórica das políticas públicas de saúde no Brasil foi subdividido em cinco partes, ficando cada grupo responsável por discutir e apresentar um trecho do artigo. 
Posteriormente, procedeu-se à explanação sobre a metodologia de apresentação e discussão propriamente dita. Nessa etapa, os alunos foram orientados a montar uma apresentação da parte do artigo sob responsabilidade do grupo em que estavam, utilizando a metodologia da construção dos mapas conceituais, de forma manual.

Foram disponibilizados para os alunos folhas A4, fitas adesivas, pincéis, lápis e borrachas. Os discentes foram apoiados pela monitora e pela docente da disciplina. Durante a realização dessa etapa, foi possível perceber que as principais dificuldades dos educandos diziam respeito à introdução das palavras de ligação que permitem a relação entre os conceitos, além de muitos apresentarem dificuldades relativas à definição do conceito principal. Essa etapa durou cerca de quarenta minutos.

Após os quarenta minutos destinados à elaboração dos mapas conceituais, procederam-se as apresentações e discussões dos grupos de trabalhos. Cada um deles utilizou em média dez minutos para a apresentação. Os mapas conceituais eram apresentados à turma, e, concomitantemente, o artigo foi sendo discutido por todos na totalidade.

Ao término da apresentação e da discussão, os educandos foram orientados a elaborar outro mapa conceitual utilizando os softwares anteriormente apresentados, porém com outro tema da disciplina. Essa atividade foi realizada a distância e apresentada em sala de aula posteriormente.

Para finalizar, os alunos e a monitora foram convidados a se posicionarem sobre a prática, e as reflexões foram muito construtivas e pertinentes aos preceitos da aprendizagem significativa, tendo no educando o agente ativo do processo.

\section{VIVÊNCIA DOS DISCENTES}

É importante ratificar que participaram da experiência trinta alunos do 8o período de um curso noturno de graduação (todos foram identificados pela letra $D$ acompanhada pelo algarismo numérico segundo a ordem da abordagem) e uma monitora. Todos se mostraram muito receptivos e interagiram bem com a nova proposta metodológica. Os depoimentos foram coletados e gravados em áudio (no primeiro semestre de 2015), sendo posteriormente transcritos na íntegra para análise. Durante a realização das atividades, ficaram evidentes a participação de todos os membros do grupo na busca pela construção do melhor mapa 
conceitual e o comprometimento de todos no momento das apresentações. Cabe destacar que, nesse momento, o domínio do tema também foi algo significativo no processo de ensinoaprendizagem.

Durante as apresentações, vários alunos reforçaram a importância da utilização dos mapas conceituais, alegando que esse tipo de metodologia torna mais fácil a percepção e a compreensão do tema proposto, ratificando a afirmação de que tal ferramenta apresenta uma "nova" maneira de organizar, estruturar e hierarquizar os conteúdos de disciplinas - ou de qualquer assunto ou tema -, por meio da organização cognitiva daqueles que os elaboram, proporcionando não somente a organização de um dado ou informação meramente disponível, mas também conhecimento e inteligência (SILVA, 2015).

Ao serem interpelados sobre o que acharam da primeira experiência com essa metodologia, muitos destacaram que o primeiro contato não foi fácil de ser operacionalizado, mas que a prática poderá permitir melhores resultados. Algumas falas exemplificam bem tais apontamentos, como as transcritas a seguir.
D1: "Difícil, complexo".
D4: "Até conseguir pegar, é difícil".
D7: "Difícil a princípio, mas depois leva a uma boa didática".

Contudo, ao serem questionados sobre a valia da elaboração dos mapas conceituais, todos concordaram que são muito oportunos para a prática acadêmica e que podem ser excelentes ferramentas de apoio a estudos, pesquisas e organização de conceitos necessários à prática profissional. As falas a seguir exemplificam tais reflexões.
D2: "Ótimo instrumento de fixação".
D3: "Prático para estudos posteriores".
D5: "Uma boa alternativa para estudar para um concurso cujo tema é complexo, pois separa as palavras que nos servirão de base".
D6: "Fixar a matéria pelas palavras de ligação".

Após esses dois questionamentos e algumas discussões, abriu-se um espaço para reflexão, e muitos alunos lamentaram não conhecerem, até então, essa estratégia metodológica. Tal lamentação era justificada, por já terem vivenciado outras disciplinas que também 
apresentavam conteúdos muito densos, nas quais os mapas conceituais poderiam ter auxiliado os estudos.

D8: "Pena eu não saber disso antes. Já poderia estar me ajudando muito...".

\section{VIVÊNCIA DA MONITORA}

Como mencionado anteriormente, a monitora não obtinha um conhecimento sólido acerca dos mapas conceituais, possuía apenas uma informação prévia, adquirida por meio de leituras sobre o tema e os pontos positivos da ferramenta.

Após compreender a metodologia e auxiliar os alunos em sala de aula, a monitora foi questionada a respeito da percepção geral que obteve durante a realização da atividade. Segundo ela, foi possível apreender, principalmente, o quão importante é essa prática na discussão de um determinado tema.

Monitora:"(...) saber utilizar os mapas é mesmo muito importante para os alunos e facilita o estudo".

Pela experiência da construção do primeiro mapa com os discentes, a monitora conseguiu perceber, também, que esse é um meio interativo e prático para entender determinado assunto. Concluiu que os alunos, ao desenvolverem esse tipo de atividade, mantinham-se mais concentrados, pois a estratégia exige discussão constante entre os membros do grupo acerca do tema analisado, para que o conteúdo se torne claro para todos os participantes.

Monitora: "Achei muito legal e 'bunitinho' [sic] eles todos concentrados e todo mundo discutindo, tentando elaborar o melhor mapa que podiam. Foi claro o quanto estavam focados e comprometidos com a dinâmica. Até o tom de voz ficou bem baixinho (risos)".

Afirmou que acredita no sucesso da metodologia e que pretende utilizá-la na prática discente e, no futuro, como docente.

Monitora: "Achei ótimo, levarei sempre comigo...(risos)".

A aprendizagem significativa ocorre quando a nova informação se ancora em conceitos ou proposições relevantes, preexistentes na estrutura cognitiva do indivíduo (SILVA, 2015). Ela não 
acontece de maneira abrupta (ou súbita), ou seja, a captação e a internalização de significados ocorrem de forma progressiva e dependem de "negociação" de significados (MOREIRA, 2013).

\section{REFLEXÃO DOCENTE}

Em geral, os alunos gostaram muito da vivência e mencionaram a importância de se utilizar ainda mais essa estratégia em outras disciplinas e pesquisas. Essa experiência trouxe à tona reflexões sobre o quão importante é a capacitação docente e a significância da mudança do perfil do educando como ser ativo no processo de formação, com estimulação por parte dos atores envolvidos (discentes e docentes).

Entretanto, para estimular, é preciso conhecer. Assim, a capacitação docente é algo diferencial e capaz de promover singulares mudanças na prática educadora, acompanhando uma tendência natural nas inovações didático-pedagógicas.

Inovar para a prática docente é algo desafiador e ainda alicerçado por paradigmas sociais contemporâneos, que fragilizam o processo de ensino-aprendizagem, reforçando o modelo tradicional, no qual o educando se apresenta como agente passivo e apenas receptor de informações.

Essa experiência permitiu galgar o desafio da inovação metodológica e motivar o educando a ser e a se manter como agente ativo, capaz de partilhar novos conhecimentos e reforçar aqueles adquiridos anteriormente.

Práticas metodológicas inovadoras, que permitem ao educando participar ativamente do processo de ensino-aprendizagem, podem se refletir na construção da carreira acadêmica do discente e gerar impactos positivos na dinâmica profissional.

\section{DISCUSSÃO}

Entende-se que os mapas conceituais têm grande potencial de serem utilizados no âmbito do ensino/educação, por se tratar de um instrumento/ferramenta que permite transformar o ensino e a aprendizagem. 
No entanto, publicações científicas que relatem essa experiência ainda parecem ser tímidas em nosso meio, dificultando, assim, o processo de discussão e de tomadas de decisão por parte dos docentes que desejam incluir novidades em sala de aula utilizando essa ferramenta.

Docentes que possuem receio de inovar em sala de aula, por não dominarem alguns recursos tecnológicos ou por simples medo e insegurança no processo de inserção do novo, são ainda numerosos. Contudo, os educadores estão cada dia mais conscientes de que as mudanças pelas quais o ensino tem passado faz com que eles busquem novas estratégias de capacitação, com vias a inovar nas práticas pedagógicas (MOREIRA, 2010).

$\mathrm{Na}$ experiência vivenciada e aqui relatada, foi necessária a capacitação docente, como sustentáculo para transpor o receio da inovação, otimizando, assim, a implementação dessa nova ferramenta metodológica.

Cabe destacar aqui que os mapas conceituais têm características que permitem uma modificação na educação tradicional, em que a aprendizagem passa a ser centrada no aluno, e não no professor, favorecendo, assim, a organização e a representação do conhecimento (MOREIRA, 2013).

Com a confecção dos mapas conceituais, os educandos se mostraram mais ativos, envolvidos e com domínio do conteúdo apresentado. O teor informativo do texto explorado foi apreendido de forma a possibilitar a solidificação da aprendizagem e a formação acadêmica.

Corroborando com essa reflexão, confirma-se o quanto essa ferramenta auxilia o crescimento do indivíduo como pessoa, e não somente como aluno, além de propiciar o conhecimento e/ ou o entendimento, e não apenas a memorização do conteúdo. É um instrumento facilitador do processo de aprendizagem, que pode ser utilizado como instrumento de avaliação (SILVA, 2015).

Nos dias atuais, com o avanço tecnológico e o partilhamento acelerado dos conteúdos, os alunos têm demandado do corpo docente práticas inovadoras de ensino, com o objetivo de melhor sistematizar e apreender as informações.

Nessa experiência acadêmica, a construção dos mapas conceituais foi capaz de auxiliar os alunos na sistematização de conceitos, sendo essa ferramenta bem aceita pelos envolvidos no trabalho e entendida como uma prática inovadora diferencial para a aprendizagem. Destaca- 
se a necessidade de educandos e educadores estarem em sintonia para alcançar resultados satisfatórios.

Assim, cabe reiterar que o uso de novas estratégias é algo desafiador, pois requer um comprometimento contínuo por parte do aluno e do professor, que, além dos mapas conceituais, pode lançar mão de um bom livro didático, recursos como internet, televisão, cinemas, dentre outras estratégias, para fazer uma educação diferenciada e de qualidade (BRASLAVSKY, 2005; SOUZA, 2010; LEITE, 2013).

\section{CONSIDERAÇÕES FINAIS}

Os Percursos Formativos em Docência do Ensino Superior permitem refletir sobre o quanto é importante a inovação docente, as estratégias para implantação e o estímulo à ação ativa do aluno em sala de aula.

Buscar novas estratégias de inovação é sempre necessário, para que o docente acompanhe o mundo, que está em constante transformação, e, assim, possa oferecer ao educando atrativos para melhor construção e partilha do saber.

A divulgação dos resultados dessa experiência poderá contribuir com educadores e educandos na ponderação sobre implementação de novas estratégias metodológicas e fazê-los refletir quanto à importância da busca pela capacitação e pela inovação na educação.

Nesse contexto, a UFMG, mais uma vez, se destaca por disponibilizar ao corpo docente e aos pós-graduandos da instituição esse espaço de formação, capacitação e qualificação, com vias a contribuir socialmente com a formação de profissionais críticos, reflexivos, autônomos e comprometidos com o bem comum, elementos essenciais para o exercício profissional e cidadão.

\section{REFERÊNCIAS}

AUSUBEL, D. The acquisition and retention of knowledge: a cognitive view. Boston: Kluwer Academic Publishers, 2000. 
BAPTISTA, M. L. M.; FREIRE, S.; FREIRE, A. M. Tarefas de investigação em aulas de física: um estudo com alunos do 8a ano. Caderno Pedagógico, Lajeado, v. 10, n. 1, p. 137-151, 2013.

BRASLAVSKY, C. Dez fatores para uma educação de qualidade para todos no século XXI. São Paulo: Moderna, 2005.

DUTRA, I.; FAGUNDES, L.; CANAS, A. Mapas conceituais. Disponível em: <http://cmap. upb.edu.co/rid=1158847644312_1415988059_19093/mapas_piaget.pdf>. Acesso em: 8 jun. 2015.

FAGUNDES, L. C.; MAÇADA, D. L.; SATO, L. S. Aprendizes do futuro: as inovações começaram! Brasília: Estação Palavra, 2000.

FREIRE, P. Pedagogia da autonomia: saberes necessários à prática educativa. São Paulo: Paz e Terra, 1996.

LEITE, S. B. Fórum estadual permanente de apoio à formação docente do Rio Grande do Sul: plano estratégico de formação de professores do estado. 2013. 142 f. Dissertação (Mestrado em Educação) - Faculdade de Educação, Universidade Federal do Rio Grande do Sul, Porto Alegre, 2013. Disponível em: <http://www.lume.ufrgs.br/bitstream/ handle/10183/72142/000882265.pdf>. Acesso em: 22 jul. 2016.

MANTOVANI, A. M. Interação, colaboração e cooperação em ambiente da aprendizagem computacional. Blog pedagógico - Laboratórios de Informática UNILASALLE. Porto Alegre: UFRGS, [s.d.]. Artigo elaborado para a oficina de Blogs Pedagógicos, Programa de Pós-Graduação em Informática na Educação. Oficinas Virtuais de Aprendizagem II, 2008. Disponível em: <http://www.labin.unilasalle.edu.br/infoedu/blog_pedagogico/textos/ texto_interacao.pdf>. Acesso em: 8 jun. 2015.

MELCHIOR, M. C. O sucesso escolar através da avaliação e da repercussão. Porto Alegre: Premier, 2001.

MOREIRA, M. A. Mapas conceituais e aprendizagem significativa. São Paulo: Centauro, 2010. Disponível em: <http://www.if.ufrgs.br/ moreira/mapasport.pdf>. Acesso em: 8 jun. 2015.

MOREIRA, M. A. Aprendizagem significativa em mapas conceituais. Porto Alegre: UFRGS, Instituto de Física, 2013.

NOVAK, J. D. How do we learn our lesson? Taking students through the process. The Science Teacher, v. 60, n. 3, p. 50-55, 1993. 
NOVAK, J. D.; CANAS, A. J. The Theory Underlaying Concept Maps and how to construct them. Institute for Human and Machine Cognition: Pensacola, 2003. Disponivel em: <http://cmap.ihmc.us/publications/researchpapers/theorycmaps/ theoryunderlyingconceptmaps.htm>. Acesso em: 8 jun. 2015.

PELIZZARI, A.; KRIEGL, M. L.; BARON, M. P.; FINCK, N. T. L.; DOROCINSKI, S. I. Teoria da aprendizagem significativa segundo Ausubel. Rev. PEC, Curitiba, v. 2, n. 1, p. 37-42, jul. 2001-jul. 2002.

PRADO, C.; VAZ, D. R.; ALMEIDA, D. M. Teoria da aprendizagem significativa: elaboração e avaliação de aula virtual na plataforma Moodle. Revista Brasileira de Enfermagem, v. 64, n. 6, p. 1.114-21, 2011.

SILVA, E. C. Mapas conceituais: propostas de aprendizagem e avaliação. Administração: ensino e pesquisa, Rio de Janeiro, v. 16, n. 4, p. 785-815, 2015.

SOUZA, N. A.; BORUCHOVITCH, E. Mapas conceituais: estratégia de ensino/aprendizagem e ferramenta avaliativa. Educação em Revista, Belo Horizonte, v. 26, n. 3, p. 195-218, 2010.

VIEIRA, F. M. S. A utilização das novas tecnologias na educação numa perspectiva construtivista. In: Anais da 22 Superintendência Regional de Ensino de Montes Claros Núcleo de Tecnologia Educacional - MG7 - Prolnfo - MEC, 2005. Disponível em: <http:// www.proinfo.mec.gov.br/upload/biblioteca/191.pdf>. Acesso em: 8 jun. 2015.

\section{Karla Rona da Silva}

Doutora em Biomedicina pelo Instituto de Ensino e Pesquisa da Santa Casa de Belo Horizonte (2013). Mestre em Ciências da Saúde pela UNINCOR/Betim (2009). Especialista em Urgência e Atendimento Pré-Hospitalar Móvel pela Universidade Estácio de Sá/BH (2006). Possui graduação em Enfermagem pela Pontifícia Universidade Católica de Minas Gerais (2005). Atualmente é professora adjunta do Departamento de Enfermagem Aplicada da Escola de Enfermagem da Universidade Federal de Minas Gerais (EE/UFMG), no curso de Gestão de Serviços de Saúde. Membro titular no grupo de pesquisa do Núcleo de Gestão em Saúde (NUGES) da EE/UFMG e no grupo de pesquisa do Núcleo de Pesquisa em Enfermagem e Saúde (NUPES) da Pontifícia Universidade Católica de Minas Gerais.

karlarona@bol.com.br 


\section{Marina Dayrell de Oliveira Lima}

Possui graduação em Enfermagem pela Faculdade Ciências Médicas de Minas Gerais (2015). Pós-graduada em Auditoria e Gestão da Qualidade Aplicada aos Serviços de Saúde pelo Centro Universitário UNA (2016).

marina_dayrell@hotmail.com

\section{Leila de Fátima Santos}

Doutoranda em Cirurgia e Oftalmologia pela Faculdade de Medicina da Universidade Federal de Minas Gerais (2017). Mestre em Administração pela Faculdade Novos Horizontes (2010). Especialista em Enfermagem do Trabalho pela Faculdade de Enfermagem Luiza de Marillac (FELM) - Centro Educacional São Camilo (2007). Graduada em Enfermagem pela Pontifícia Universidade Católica de Minas Gerais (2003). Atualmente é docente da Faculdade Ciências Médicas de Minas Gerais (FCM-MG) e do Instituto de Educação Continuada da Pontifícia Universidade Católica de Minas Gerais (IEC-PUC MINAS). Membro da Núcleo de Ensino da FCM-MG com foco no Planejamento e na Gestão de Estágios Obrigatórios.

leila.santos@gmail.com 